\title{
Time-Dependent Increases in Brain-Derived Neurotrophic Factor Protein Levels within the Mesolimbic Dopamine System after Withdrawal from Cocaine: Implications for Incubation of Cocaine Craving
}

\author{
Jeffrey W. Grimm, ${ }^{1 *}$ Lin Lu, ${ }^{1 \star}$ Teruo Hayashi, ${ }^{2 \star}$ Bruce T. Hope, ${ }^{1}$ Tsung-Ping Su, ${ }^{2}$ and Yavin Shaham ${ }^{1}$ \\ ${ }^{1}$ Behavioral Neuroscience Branch and ${ }^{2}$ Cellular Neurobiology Branch, Intramural Research Program/National Institute on Drug Abuse/National Institutes \\ of Health/Department of Health and Human Services, Baltimore, Maryland 21224
}

\begin{abstract}
Using a rat model of drug craving, we found that the responsiveness to cocaine cues progressively increases or incubates over the first $60 \mathrm{~d}$ of cocaine withdrawal. Here we studied whether alterations in brain-derived neurotrophic factor (BDNF) protein levels within the mesolimbic dopamine system are associated with this incubation phenomenon. BDNF is involved in synaptic plasticity and was found to enhance responding for cues associated with natural rewards. Rats were trained to press a lever to receive intravenous cocaine or oral sucrose for $6 \mathrm{hr} / \mathrm{d}$ for $10 \mathrm{~d}$; each earned reward was paired with a tone-light cue. Resumption of lever-pressing behavior was then assessed on days 1,30, or 90 of reward withdrawal. First, resistance to extinction was assessed during $6 \mathrm{hr}$ in which lever presses were not reinforced and the cue was absent. Second, cue-induced reinstatement was assessed after extinction during $1 \mathrm{hr}$ in which responding led to cue presentations. Other rats were killed without testing on days 1,30 , and 90 of reward withdrawal, and BDNF and nerve growth factor (NGF) protein levels were measured in the ventral tegmental area (VTA), accumbens, and amygdala. Lever pressing during extinction and cue-induced reinstatement tests of cocaine craving progressively increased after cocaine withdrawal. Time-dependent changes also were observed during the tests for sucrose craving, with maximal responding on day 30. BDNF, but not NGF, levels in the VTA, accumbens, and amygdala progressively increased after cocaine, but not sucrose, withdrawal. Time-dependent increases in BDNF levels may lead to synaptic modifications that underlie enhanced responsiveness to cocaine cues after prolonged withdrawal periods.
\end{abstract}

Key words: amygdala; extinction; nucleus accumbens; reinstatement; relapse; ventral tegmental area

\section{Introduction}

Cocaine addiction is characterized by high rates of relapse after prolonged abstinence (O'Brien, 1997). This relapse is often associated with reports of craving, a subjective state induced by reexposure to stimuli associated with cocaine intake (Childress et al., 1999). Based on clinical observations, Gawin and Kleber (1986) hypothesized that cue-induced cocaine craving progressively increases during drug abstinence. Recently, we described an analogous phenomenon in a study in which we inferred cocaine craving from the responsiveness of rats to cocaine cues in two tests performed after withdrawal from drug selfadministration (Grimm et al., 2001). First, resistance to extinc-

Received Sept. 9, 2002; revised 0ct. 25, 2002; accepted Nov. 13, 2002.

This work was supported by the National Institute on Drug Abuse, Intramural Research Program. We thank Drs. Roy Wise, Barry Hoffer, and Yun Wang for helpful suggestions and Kelly Badger and Polly Robarts for technical assistance.

*J.W.G., L.L., and T.H. contributed equally to this work.

Correspondence should be addressed to Dr. Yavin Shaham, Behavioral Neuroscience Branch, Intramural Research Program/National Institute on Drug Abuse/National Institutes of Health, 5500 Nathan Shock Drive, Baltimore, MD 21224. E-mail: yshaham@intra.nida.nih.gov.

J. W. Grimm's present address: Department of Psychology, Western Washington University, 516 High Street, Bellingham, WA 98225-9089.

Copyright $\odot 2003$ Society for Neuroscience $\quad 0270-6474 / 03 / 230742-06 \$ 15.00 / 0$ tion was assessed in the presence of the house light and the lever, contextual cues that during training had indicated drug availability, but in the absence of cocaine and a discrete tone-light cue previously paired with drug injections. Second, cue-induced reinstatement of cocaine seeking was assessed in a test wherein responding led to the tone-light cue presentations under extinction conditions. We found that the responsiveness to cocaine cues progressively increases or incubates over the first $60 \mathrm{~d}$ of withdrawal. This "incubation of craving" may be mediated by neuroadaptations within the mesolimbic dopamine (DA) reward system that are induced by chronic cocaine self-administration and subsequent withdrawal (Nestler and Aghajanian, 1997; Piazza and Le Moal, 1997; White and Kalivas, 1998). Some of these neuroadaptations might include molecular (Nestler, 2001) and morphological (Robinson and Berridge, 2003) changes involved in synaptic plasticity associated with learning and memory (Hyman and Malenka, 2001).

Brain-derived neurotrophic factor (BDNF) is a growth factor involved in synaptic plasticity (Thoenen, 1995) and in cellular events thought to underlie learning and memory processes such as long-term potentiation (LTP) (Yamada et al., 2002). BDNF colocalizes with tyrosine hydroxylase in midbrain DA neurons (Seroogy et al., 1994) and therefore, can play a role in synaptic 
plasticity of these neurons (Hyman and Malenka, 2001). BDNF infusions into the substantia nigra, ventral tegmental area (VTA), and accumbens increase DA utilization and enhance locomotor activity induced by psychostimulant drugs (for review, see Pierce and Bari, 2001). Accumbens infusions of BDNF also enhance responding for conditioned stimuli paired with water reward (Horger et al., 1999). Primarily based on this latter finding, we studied whether alterations in BDNF protein levels within the mesolimbic DA system are associated with the time-dependent changes in responsiveness to cocaine cues after withdrawal.

We trained rats to lever-press for intravenous cocaine or oral sucrose, a control condition using nondrug reward. Responsiveness to the reward-associated cues was then assessed on days 1 , 30 , or 90 of withdrawal in tests for resistance to extinction and cue-induced reinstatement. Other rats were killed without testing after reward withdrawal, and BDNF and nerve growth factor (NGF) protein levels were measured using ELISA in the VTA, accumbens, and amygdala. Thus, we determined long-term changes in BDNF protein levels that are not influenced by the potential acute induction of BDNF provoked by re-exposure to a reinforcer-associated environment (Hall et al., 2000). NGF was used as a control growth factor because it is not colocalized with midbrain DA neurons (Seroogy et al., 1994) and does not alter cocaine-induced locomotion (Pierce and Bari, 2001). The VTA, accumbens, and amygdala are involved in reinstatement of cocaine seeking (Stewart, 2000; Shalev et al., 2002) and responding for conditioned rewards (Everitt et al., 1999).

\section{Materials and Methods}

Subjects and surgery

Male Long-Evans rats (Charles River, Raleigh, NC; 350-400 gm) were used. Rats were housed in the animal facility and were maintained on a reversed $12 \mathrm{hr}$ light/dark cycle (lights off at 10 A.M.) with food and water available in the home cage. Procedures followed the Principles of Laboratory Animal Care (National Institutes of Health publication 86-23, 1996). Rats were surgically implanted with intravenous catheters (Grimm et al., 2002) under anesthesia (xylazine plus ketamine, 10 plus $100 \mathrm{mg} / \mathrm{kg}$, i.p.). Buprenorphine $(0.01 \mathrm{mg} / \mathrm{kg})$ was administered before surgery. Catheters were flushed with saline every $24-48 \mathrm{hr}$ during a $5 \mathrm{~d}$ recovery period and before the drug self-administration sessions. Sucrose-trained rats underwent intravenous "sham" surgery.

\section{Apparatus}

The self-administration boxes, controlled by a Med Associates (Georgia, VT) system, had two levers located $9 \mathrm{~cm}$ above the grid floor, but only one lever (an active, retractable lever) activated the infusion pump. Presses on the other lever (an inactive, stationary lever) were also recorded. The modified cannula on the rat's skull was connected to a liquid swivel with polyethylene-50 tubing that was protected by a metal spring and connected to the syringe of the infusion pump. The sucrose solution was delivered into liquid-drop receptacles.

\section{Procedures}

The experiments included three phases. During the training phase (10 d), rats were trained to lever-press for cocaine or sucrose; each earned reward was paired with a discrete tone-light cue. During the withdrawal phase (1-90 d), rats were housed in the animal facility. During the test day, lever presses were not rewarded. Initially, rats were allowed to leverpress for six to eight $1 \mathrm{hr}$ sessions ("extinction of lever-pressing behavior") in the absence of the tone-light cue. Rats were then tested for reinstatement induced by contingent presentations of this cue during one $1 \mathrm{hr}$ session. In experiment 2, rats were trained to self-administer cocaine or sucrose but were not exposed to the test conditions after withdrawal.

\section{Training phase}

Rats were trained to self-administer cocaine (supplied by the National Institute on Drug Abuse; dissolved in saline; $1.0 \mathrm{mg} / \mathrm{kg}$ per infusion; delivered over $4.5 \mathrm{sec}$ ) or $10 \%$ sucrose solution $(0.4 \mathrm{ml}$ per reward delivery). Rats were housed in the animal facility and were brought to the self-administration chambers every day. Training was conducted during six $1 \mathrm{hr}$ daily sessions that were separated by $5 \mathrm{~min}$ for $10 \mathrm{~d}$ under a continuous reinforcement schedule (each lever press is reinforced) with a $40 \mathrm{sec}$ timeout after each earned reward. To facilitate sucrose training, water was not available on the day before training. For rats that did not initiate cocaine self-administration, food was removed from the chambers during the six $1 \mathrm{hr}$ sessions for up to $5 \mathrm{~d}$. Each session began with the insertion of the active lever and the illumination of a red house light. Each earned reward was accompanied by a $5 \mathrm{sec}$ tone-light cue. At the end of each session, the house light was turned off and the active lever was retracted. The number of rewards earned was limited to 15 per hour to minimize cocaine overdose or for preventing the sucrose-trained rats from emptying the syringes.

\section{Withdrawal phase}

Rats were housed in the animal facility and were handled three times per week. In experiment 1 , independent groups were then tested for sucrose or cocaine seeking at the different withdrawal periods. In experiment 2 , rats were neither tested nor exposed to the self-administration chambers after withdrawal.

\section{Experiment 1: extinction responding and cue-induced} reinstatement of reward seeking

Cocaine-trained rats. Three groups ( $n=11-12$ per group) of rats were tested for resistance to extinction and cue-induced reinstatement after 1 , 30 , or $90 \mathrm{~d}$ of withdrawal. Cocaine-trained rats were connected to the metal spring, but neither cocaine nor its vehicle (saline) was available during testing. On the test day, resumption of lever pressing was assessed in two ways. First, resistance to extinction was assessed in the absence of the discrete tone-light cue previously paired with cocaine injections. Rats were allowed to lever-press for six to eight $1 \mathrm{hr}$ sessions (separated by 5 min intervals when the lever was retracted and the house light was turned off) until they met an extinction criterion of $\leq 15$ responses per session on the active lever. Second, a test for cue-induced reinstatement was conducted $5 \mathrm{~min}$ after the final extinction session. Each lever press resulted in another presentation of the tone-light cue that served as a conditioned reinforcer (Robbins et al., 1989) during this test. A single, noncontingent presentation of the cue was given at the onset of the test session because toward the end of extinction, several rats did not approach the lever.

Sucrose-trained rats. Three groups of rats $(n=10-14)$ were tested for resistance to extinction and cue-induced reinstatement after 1,30 , or $90 \mathrm{~d}$ of withdrawal from sucrose under conditions identical to those described above.

\section{Experiment 2: BDNF and NGF protein levels}

Rats from six groups ( $n=5-7$ per group) were decapitated 1,30 , or $90 \mathrm{~d}$ after withdrawal from sucrose or cocaine self-administration, and their brains were then removed. A control group of naive rats $(n=5)$ was also included in the assays. Brains were rapidly extracted, frozen in $-50^{\circ} \mathrm{C}$ isopentane, and stored at $-80^{\circ} \mathrm{C}$. Bilateral tissue punches of the VTA, accumbens, and amygdala were obtained from $\sim 1 \mathrm{~mm}$ coronal sections cut in a cryostat at $-20^{\circ} \mathrm{C}$. The coronal sections were approximately $-5.6,+1.8$, and $-2.3 \mathrm{~mm}$ from bregma for the VTA, accumbens (core and shell), and amygdala (central and basolateral), respectively (Paxinos and Watson, 1998). Tissue punches were sonicated in $300 \mu \mathrm{l}$ of lysis buffer (137 mm NaCl, $20 \mathrm{~mm}$ Tris, 1\% NP-40, 10\% glycerol, $1 \mathrm{~mm}$ phenylmethylsulfonyl fluoride, $10 \mu \mathrm{g} / \mathrm{ml}$ aprotinin, $1 \mu \mathrm{g} / \mathrm{ml}$ leupeptin, and $0.5 \mathrm{~mm}$ sodium vanadate). The homogenates were incubated at $4^{\circ} \mathrm{C}$ for $30 \mathrm{~min}$ and centrifuged at $12,000 \times g$ for $10 \mathrm{~min}$. The protein concentrations of the supernatants were determined using the Micro-BCA assay kit (Pierce, Rockford, IL). Sandwich-style ELISAs were performed using the BDNF and NGF Emax ImmunoAssay System kit (Promega, Madison, WI) according to the manufacturer's instructions (Wang et al., 2000). BDNF and NGF content were interpolated from standard curve runs for each plate (linear range of 7.8-500 and 16-1000 pg/ml for BDNF and NGF, respectively). BDNF and NGF protein contents were divided by total protein in each sample to determine the number of 
picograms of peptide per microgram of total protein. For a given brain area and growth factor, samples from the groups of cocaine- and sucrosetrained rats and the naive control rats were determined in a single run. The intra-assay variability values were $2.46 \pm 1.53 \%$ (mean \pm SD) and $3.43 \pm 3.90 \%$ for BDNF and NGF, respectively.

\section{Statistical analyses}

Data from the extinction sessions and tests for cue-induced reinstatement were analyzed separately for total (nonreinforced) active and inactive lever responses. Data were analyzed separately for the cocaine- and sucrose-trained rats.

Extinction responding. A mixed-model ANOVA was conducted using the between-subjects factor of withdrawal period $(1,30$, or $90 \mathrm{~d})$ and the within-subjects factor of session (the first six $1 \mathrm{hr}$ sessions during which all rats from all groups were exposed to the extinction conditions).

Cue-induced reinstatement. Data were analyzed for responses during the last 60 min extinction session during which rats reached the extinction criterion (baseline, no cue condition) and for responses made during the subsequent $1 \mathrm{hr}$ test. A mixed-model ANOVA was conducted using the between-subjects factor of withdrawal period and the withinsubjects factor of test session (no cue vs cue).

ELISAs. Raw values of protein levels of BDNF and NGF were analyzed with two-way ANOVAs using the between-subjects factors of withdrawal period and reward type (cocaine vs sucrose). Post hoc analyses were performed with the Fisher PLSD test, and significant differences are reported for $p<0.05$.

\section{Results}

Rats demonstrated reliable cocaine or sucrose self-administration, and no significant differences were observed within the sucrose and cocaine conditions among the groups tested at the different withdrawal days in experiments 1 and 2 . The mean \pm SEM (data collapsed for both experiments) number of earned rewards on the last three days of training were $52.9 \pm 1.8,54.4 \pm 1.9$, and $57.3 \pm 1.7$, respectively, for the cocaine-trained rats $(n=55)$ and $79.4 \pm 2.3,78.1 \pm 2.3$, and $81.4 \pm 1.9$, respectively, for the sucrose-trained rats $(n=53)$.

\section{Experiment 1: extinction responding and cue-induced reinstatement of reward seeking}

\section{Cocaine-trained rats}

Nonreinforced lever pressing during tests for resistance to extinction and cue-induced reinstatement were significantly higher after 30 and $90 \mathrm{~d}$ of withdrawal than on day 1.

Extinction responding. Figure $1 A$ and $B$ show active-lever responses in the absence of the discrete tone-light cue during the test for resistance to extinction. Figure $1 \mathrm{~A}$ also shows inactivelever responses (a measure of nonspecific activity and/or response generalization). All rats met the extinction criterion ( $\leq 15$ active-lever responses per hour) within six to eight sessions. Analysis of active-lever responding revealed significant effects of withdrawal period $\left(F_{(2,31)}=8.5 ; p=0.01\right)$, session $\left(F_{(5,155)}=\right.$ $50.6 ; p<0.01)$ and withdrawal period by session $\left(F_{(10,155)}=5.9\right.$; $p<0.01)$. The effect of withdrawal period on inactive-lever responding was not significant $(p>0.05)$.

Cue-induced reinstatement. Figure $1 C$ shows active-lever responses during the $1 \mathrm{hr}$ test session for cue-induced reinstatement in which lever presses led to the presentation of the tonelight cue that was previously paired with earned cocaine. Analysis revealed significant effects of withdrawal period $\left(F_{(2,31)}=5.3\right.$; $p<0.05)$, test session $\left(F_{(1,31)}=52.9 ; p<0.01\right)$, and withdrawal period by test session $\left(F_{(2,31)}=3.7 ; p<0.05\right)$. Inactive-lever responses were low ( $<3$ per $1 \mathrm{hr}$ session), and no group differences were found $(p>0.05)$.

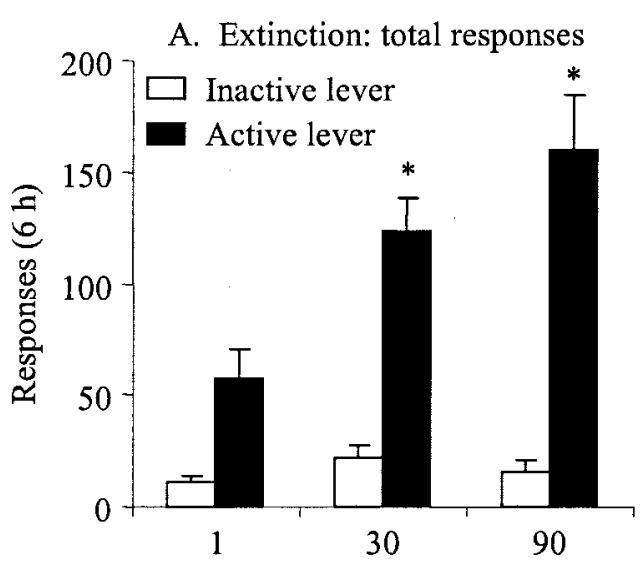

Cocaine withdrawal period (days)
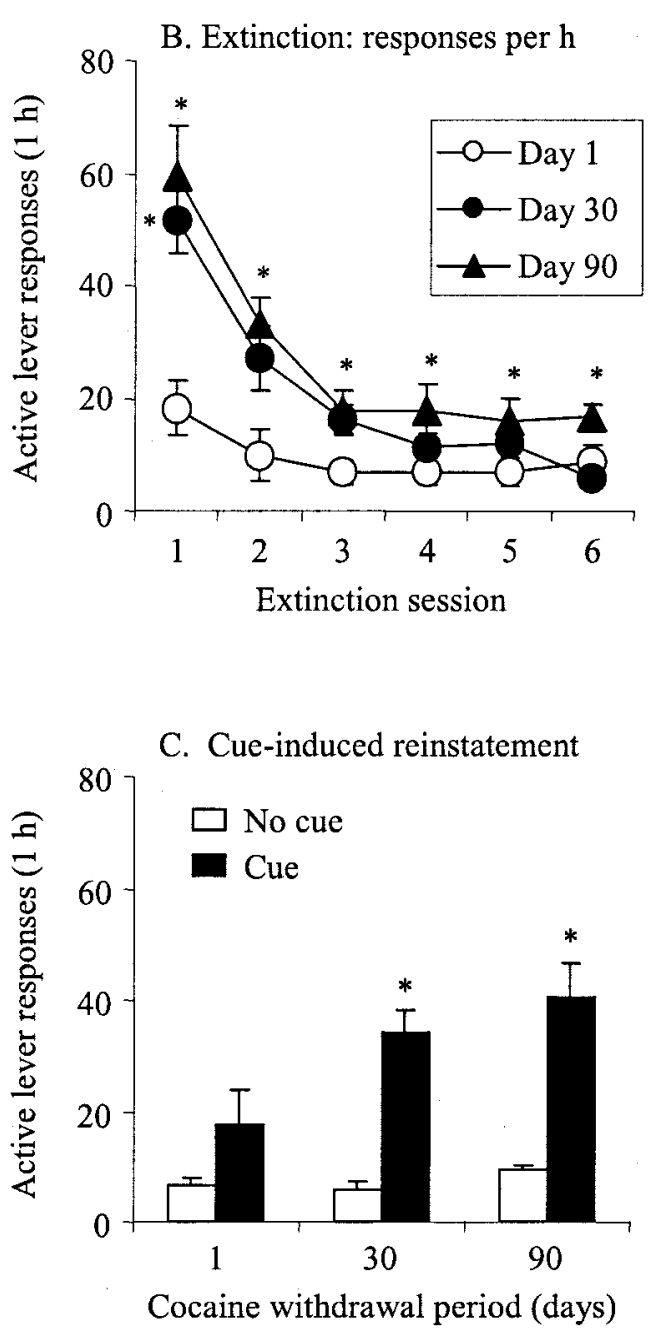

Figure 1. Cocaine. A, Extinction, total responses: mean $\pm S E M$ responses on the previously active-lever and inactive-lever responses during the six 60 min sessions of extinction (conducted in the absence of the discrete tone-light cue previously paired with cocaine infusions). $B$, Extinction, responses per hour: mean active-lever responses at each session of extinction. $C$, Cue-induced reinstatement: mean active-lever responses during the 60 min session that followed the extinction sessions. During the test for cue-induced reinstatement, lever presses led to presentations of the tone-light cue. No cue refers to the last 60 min extinction session on which the rats reached the extinction criterion. ${ }^{*}$ Different from day 1 withdrawal; $p<0.05$; Fisher PLSD ( $n=11-12$ per withdrawal period). 
Sucrose-trained rats

Nonreinforced lever pressing during tests for cue-induced reinstatement followed an inverted U-shaped function with higher responding on day 30 of withdrawal from sucrose than on days 1 and 90. A similar trend, although not statistically significant, was observed for extinction responding.

Extinction responding. Figure $2 A$ and $B$ show active- and inactive-lever responses in the absence of the discrete tone-light cue during the test for resistance to extinction. All rats met the extinction criterion ( $\leq 15$ active-lever responses per hour) within six to eight sessions. Analysis of active-lever responding revealed significant effects of session $\left(F_{(5,155)}=38.2 ; p<0.01\right)$ and an approaching significant effect of withdrawal period $\left(F_{(2,31)}=2.6\right.$; $p=0.09)$. The effect of withdrawal period on inactive-lever responding was not significant $(p>0.05)$.

Cue-induced reinstatement. Figure $2 C$ shows active-lever responses during the $1 \mathrm{hr}$ test session for cue-induced reinstatement in which lever presses led to the presentation of the tonelight cue previously paired with earned sucrose. Analysis of active-lever responding revealed significant effects of withdrawal period $\left(F_{(2,31)}=5.2 ; p<0.05\right)$, test session $\left(F_{(1,31)}=43.4 ; p<\right.$ $0.01)$, and withdrawal period by test session $\left(F_{(2,31)}=5.9 ; p<\right.$ $0.05)$. Inactive-lever responses were very low (group means of less than two per $1 \mathrm{hr}$ session), and no group differences were found $(p>0.05)$.

\section{Experiment 2: BDNF and NGF protein levels}

The data obtained from the ELISAs are presented in Figure 3. The values for the cocaine- and sucrose-trained rats are presented as the percentage of the mean values of naive control rats that were not exposed to cocaine or sucrose. Time-dependent increases in the levels of the BDNF protein, but not the NGF protein, were observed in the VTA, accumbens, and amygdala after withdrawal from cocaine. For BDNF in the VTA, analysis revealed significant effects of reward type $\left(F_{(1,24)}=6.5 ; p<0.01\right)$ and approaching significant effects of withdrawal period $\left(F_{(2,24)}=3.3 ; p<0.06\right)$ and reward type by withdrawal period $\left(F_{(1,24)}=3.2 ; p<0.06\right)$. For BDNF in the accumbens and amygdala, analysis revealed significant effects of reward type $\left(F_{(1,34)}=17.7\right.$ and $31.6 ; p<$ $0.01)$, withdrawal period $\left(F_{(2,34)}=9.5\right.$ and 9.6; $\left.p<0.01\right)$, and reward type by withdrawal period $\left(F_{(2,34)}=4.1\right.$ and $6.8 ; p<$ $0.05)$. No significant effects were observed for NGF levels in the VTA, accumbens, or amygdala $(p>0.05)$.

\section{Discussion}

The responsiveness to cocaine cues progressively increases during tests for resistance to extinction and cue-induced reinstatement and persists for up to $90 \mathrm{~d}$ of withdrawal. Significant timedependent changes in responsiveness to sucrose cues also were observed during the test for cue-induced reinstatement, but not for resistance to extinction, with peak responding after $30 \mathrm{~d}$. Most important, BDNF, but not NGF, protein levels in the VTA, accumbens, and amygdala progressively increase after withdrawal from cocaine, but not sucrose, self-administration.

The present behavioral data extend our previous findings of incubation of both sucrose and cocaine craving as measured in our model (Grimm et al., 2001, 2002). The reasons for the different time course of responding for cocaine versus sucrose cues and the less robust effect on the test for resistance for extinction for sucrose-trained rats are not known. Potential behavioral mechanisms for differences in magnitude and duration of the incubation phenomenon in cocaine- versus sucrose-trained rats, including response rates during training as well as anhedonia and

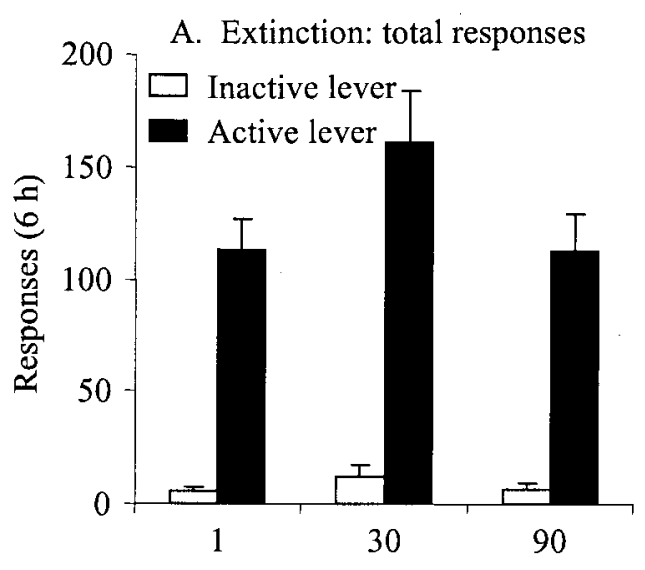

Sucrose withdrawal period (days)
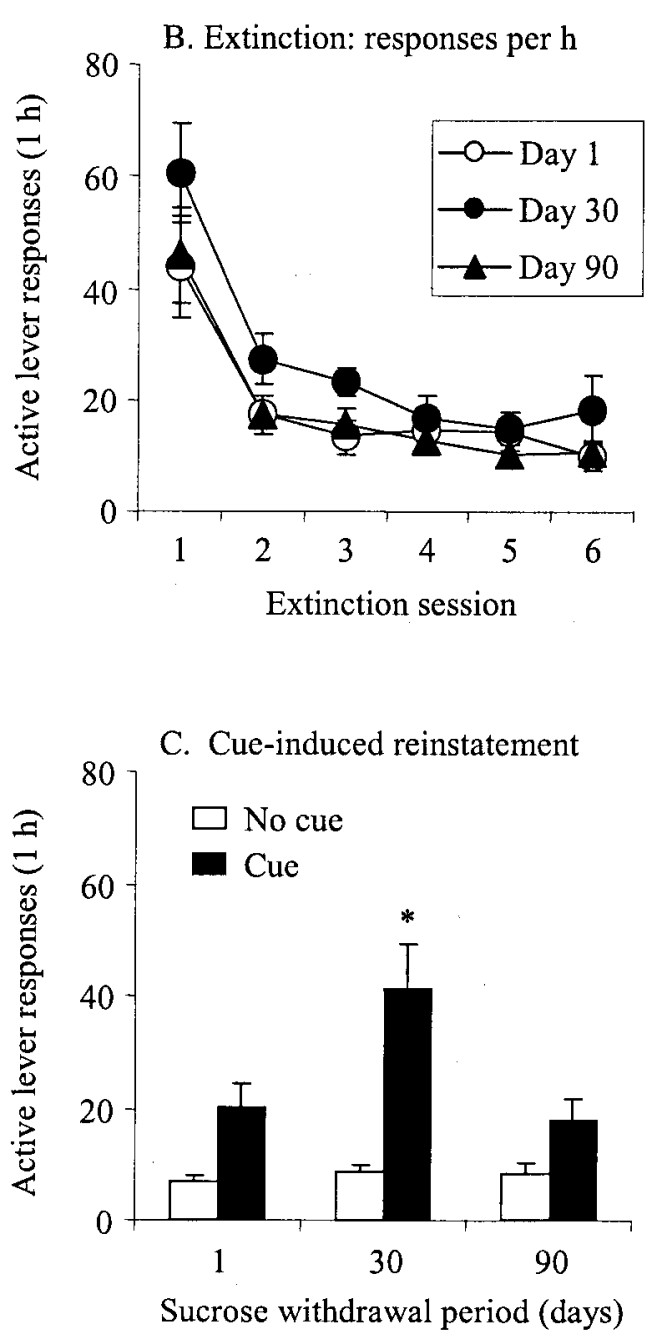

Figure 2. Sucrose. A, Extinction, total responses: mean \pm SEM responses on the previously active-lever and inactive-lever responses during the six 60 min sessions of extinction (conducted in the absence of the discrete tone-light cue previously paired with sucrose infusions). $B$, Extinction, responses per hour: mean active-lever responses at each session of extinction. $C$, Cue-induced reinstatement: mean active-lever responses during the 60 min session that followed the extinction sessions. During the test for cue-induced reinstatement, lever presses led to presentations of the tone-light cue. No cue refers to the last 60 min extinction session on which the rats reached the extinction criterion. ${ }^{*}$ Different from day 1 withdrawal; $p<0.05$ ( $n=10-14$ per withdrawal period). 
A. VTA
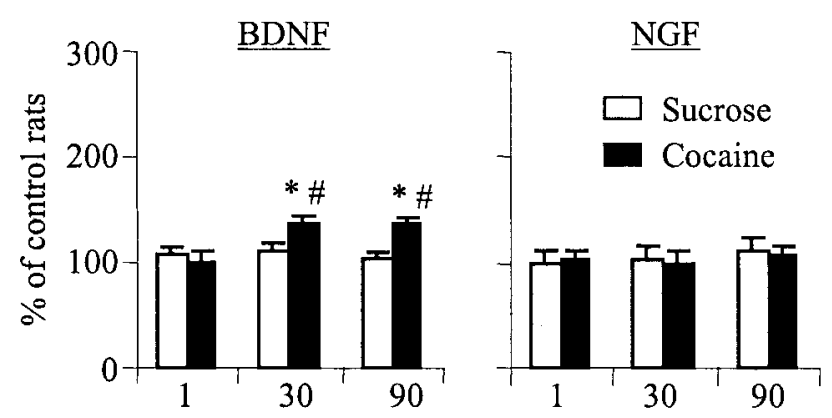

B. Accumbens
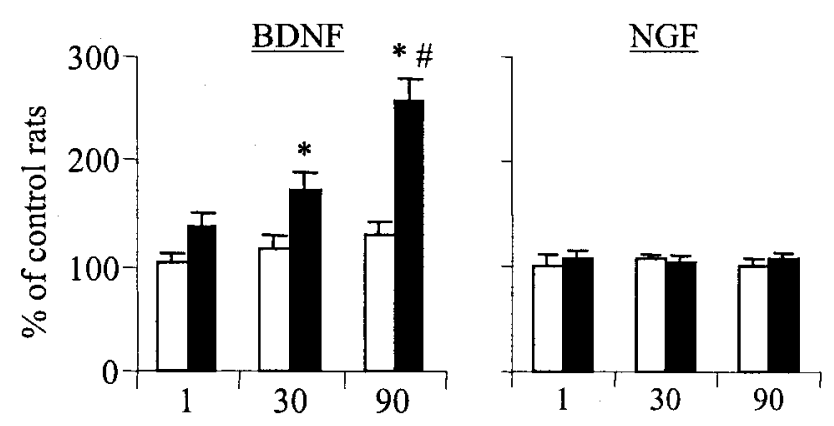

C. Amygdala
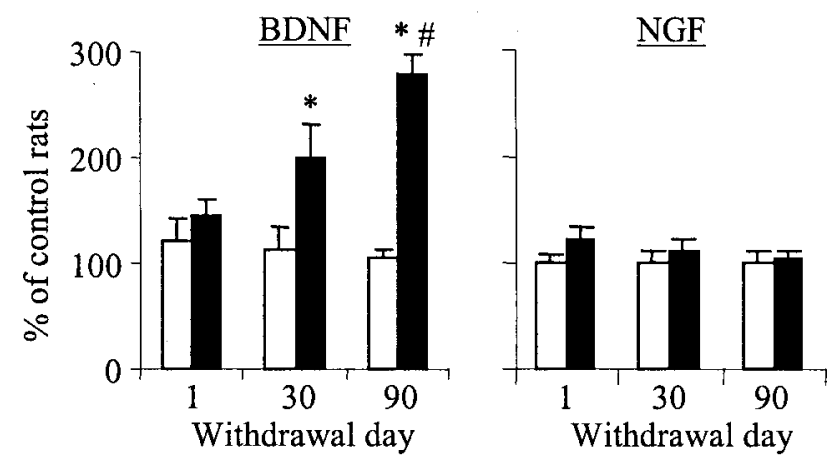

Figure 3. BDNF and NGF protein levels in VTA $(A)$, accumbens $(B)$, and amygdala ( $C$ ) after reward withdrawal. Data are presented as the percentage of mean values of naive control rats that were not exposed to sucrose or cocaine. *Different from the sucrose-trained groups at each withdrawal day; $p<0.05$. "Different from day 1 cocaine withdrawal; $p<0.05(n=5-7$ per group).

anxiety during early cocaine withdrawal have been discussed previously (Grimm et al., 2002). Below we discuss the potential role of BDNF in the persistent responsiveness to cocaine cues after withdrawal.

\section{BDNF and incubation of cocaine craving}

Although incubation of craving occurs for sucrose and cocaine, BDNF protein levels in the VTA, accumbens, and amygdala progressively increase after cocaine, but not sucrose, withdrawal. This increase in BDNF levels had a time course similar to that of responding for cocaine cues. Based on these data, we speculate that BDNF-mediated synaptic plasticity may be involved in the persistent responsiveness to cocaine cues after withdrawal. In this regard, it is of significance that both BDNF levels and cue responding were substantially elevated on day 90 of cocaine withdrawal, a time point at which responsiveness to sucrose cues was similar to that observed on day 1. BDNF is involved in the control of dendritic morphology (McFarlane, 2000). Thus, the higher levels of BDNF observed here may produce morphological changes in brain areas innervated by DA neurons; these changes have been hypothesized recently to be involved in compulsive drug use (Robinson and Berridge, 2003). This hypothesis is based on the observations that exposure to cocaine or amphetamine leads to persistent morphological changes in neurons within the mesocorticolimbic DA terminal regions, such as increases in dendritic branching and density of dendritic spines on medium spiny neurons in the nucleus accumbens shell and on pyramidal cells in the prefrontal cortex (Robinson and Kolb, 1999; Robinson et al., 2001). The present data also are potentially relevant to those from recent reports of cocaine-induced LTP in the VTA (Ungless et al., 2001) and long-term depression (LTD) in the accumbens (Thomas et al., 2001). LTP and LTD are cellular processes thought to be involved in learning and memory processes, and are dependent on BDNF activity (Yamada et al., 2002). However, the degree to which cocaine-induced LTP or LTD within the mesolimbic DA system is involved in incubation of cocaine craving is not known in the absence of data on the time course of these effects after withdrawal.

Finally, Horger et al. (1999) reported that BDNF infusions into the VTA and accumbens enhance cocaine-induced locomotor sensitization. Horger et al. (1999) also found that accumbens infusions of BDNF enhance responding for a conditioned water reward, an effect similar to that observed after repeated exposure to systemic cocaine injections (Taylor and Horger, 1999). These observations are of potential relevance to the phenomenon of incubation of craving because the time course of enhanced responsiveness to cocaine cues is somewhat similar to that of the expression of psychostimulant sensitization after withdrawal (Kalivas and Stewart, 1991; Robinson and Berridge, 1993). For example, time-dependent changes in the magnitude of amphetamine-induced psychomotor activity during tests for the expression of sensitization after withdrawal were observed for up to 1 year, with lower activity during early withdrawal (Robinson and Berridge, 1993). The degree that neuronal mechanisms underlying psychostimulant locomotor sensitization are involved in incubation of cocaine craving, however, is not known. Many studies on the expression of locomotor sensitization in cocaineexperienced rats reported that locomotor activity is sensitized during both early (first several days) and late (several weeks) withdrawal (Henry and White, 1995). However, the mechanisms underlying cocaine-induced locomotor sensitization during early withdrawal (e.g., subsensitivity of D2 autoreceptors in the VTA) are different from the ones mediating cocaine sensitization during late withdrawal (e.g., D1 receptor supersensitivity, enhanced DA and glutamate neurotransmission in the accumbens) (White and Kalivas, 1998). Thus, it is possible that the neuroadaptations associated with sensitized locomotor activity during late withdrawal also are involved in the persistence of responsiveness to cocaine cues observed here.

\section{Concluding remarks}

Time-dependent changes in responsiveness to reward cues after withdrawal are observed in both cocaine- and sucrose-trained rats, and were previously found with heroin-trained rats in a test for resistance to extinction (Shalev et al., 2001). Time-dependent 
changes in responsiveness to cues also were reported after exposure to aversive events, a phenomenon termed "incubation of fear" (Houston et al., 1999). Here we report time-dependent alterations in BDNF protein levels within the mesolimbic DA system after withdrawal from cocaine, but not sucrose, self-administration. Therefore, neuronal mechanisms other than alterations in BDNF levels are likely to be involved in the incubation phenomenon that is observed with cues previously paired with appetitive or aversive stimuli. We speculate, however, that the persistence of responding to cocaine, but not to sucrose, cues after prolonged withdrawal may involve BDNF-mediated synaptic plasticity induced by cocaine selfadministration and subsequent withdrawal. These synaptic modifications may underlie cue-induced cocaine craving and relapse after prolonged abstinence.

\section{References}

Childress AR, Mozley PD, McElgin W, Fitzgerald J, Reivich M, O'Brien CP (1999) Limbic activation during cue-induced cocaine craving. Am J Psychiatry 156:11-18.

Everitt BJ, Parkinson JA, Olmstead MC, Arroyo M, Robledo P, Robbins TW (1999) Associative processes in addiction and reward. The role of amygdala-ventral striatal subsystems. Ann NY Acad Sci 877:412-438.

Gawin FH, Kleber HD (1986) Abstinence symptomatology and psychiatric diagnosis in cocaine abusers. Clinical observations. Arch Gen Psychiatry 43:107-113.

Grimm JW, Hope BT, Wise RA, Shaham Y (2001) Incubation of cocaine craving after withdrawal. Nature 412:141-142.

Grimm JW, Shaham Y, Hope BT (2002) Effect of the cocaine and sucrose withdrawal period on extinction behavior, cue-induced reinstatement and protein levels of the dopamine transporter and tyrosine hydroxylase in limbic and cortical areas in rats. Behav Pharmacol 13:379-388.

Hall J, Thomas KL, Everitt BJ (2000) Rapid and selective induction of BDNF expression in the hippocampus during contextual learning. Nat Neurosci 3:533-535.

Henry DJ, White FJ (1995) The persistence of behavioral sensitization to cocaine parallels enhanced inhibition of nucleus accumbens neurons. J Neurosci 15:6287-6299.

Horger BA, Iyasere CA, Berhow MT, Messer CJ, Nestler EJ, Taylor JR (1999) Enhancement of locomotor activity and conditioned reward to cocaine by brain-derived neurotrophic factor. J Neurosci 19:4110-4122.

Houston FP, Stevenson GD, McNaughton BL, Barnes CA (1999) Effects of age on the generalization and incubation of memory in the F344 rat. Learn Mem 6:111-119.

Hyman SE, Malenka RC (2001) Addiction and the brain: the neurobiology of compulsion and its persistence. Nat Rev Neurosci 2:695-703.

Kalivas PW, Stewart J (1991) Dopamine transmission in the initiation and expression of drug- and stress-induced sensitization of motor activity. Brain Res Brain Res Rev 16:223-244.

McFarlane S (2000) Dendritic morphogenesis: building an arbor. Mol Neurobiol 22:1-9.

Nestler EJ (2001) Molecular basis of long-term plasticity underlying addiction. Nat Rev Neurosci 2:119-128.
Nestler EJ, Aghajanian GK (1997) Molecular and cellular basis of addiction. Science 278:58-63.

O'Brien CP (1997) A range of research-based pharmacotherapies for addiction. Science 278:66-70.

Paxinos G, Watson C (1998) The rat brain in stereotaxic coordinates, Ed 4. San Diego: Academic.

Piazza PV, Le Moal M (1997) Glucocorticoids as a biological substrate of reward: physiological and pathophysiological implications. Brain Res Brain Res Rev 25:359-372.

Pierce RC, Bari AA (2001) The role of neurotrophic factors in psychostimulantinduced behavioral and neuronal plasticity. Rev Neurosci 12:95-110.

Robbins TW, Cador M, Taylor JR, Everitt BJ (1989) Limbic-striatal interactions in reward related processes. Neurosci Biobehav Rev 13:155-162.

Robinson TE, Berridge KC (1993) The neural basis of drug craving: an incentive-sensitization theory of addiction. Brain Res Brain Res Rev 18:247-291.

Robinson TE, Berridge KC (2003) Addiction. Annu Rev Psychol 54:25-53.

Robinson TE, Kolb B (1999) Alterations in the morphology of dendrites and dendritic spines in the nucleus accumbens and prefrontal cortex following repeated treatment with amphetamine or cocaine. Eur J Neurosci 11:1598-1604.

Robinson TE, Gorny G, Mitton E, Kolb B (2001) Cocaine self-administration alters the morphology of dendrites and dendritic spines in the nucleus accumbens and neocortex. Synapse 39:257-266.

Seroogy KB, Lundgren KH, Tran TM, Guthrie KM, Isackson PJ, Gall CM (1994) Dopaminergic neurons in rat ventral midbrain express brainderived neurotrophic factor and neurotrophin-3 mRNAs. J Comp Neurol 342:321-334.

Shalev U, Morales M, Hope BT, Yap J, Shaham Y (2001) Time-dependent changes in extinction behavior and stress-induced reinstatement of drug seeking following withdrawal from heroin in rats. Psychopharmacology 156:98-107.

Shalev U, Grimm JW, Shaham Y (2002) Neurobiology of relapse to heroin and cocaine: a review. Pharmacol Rev 54:1-42.

Stewart J (2000) Pathways to relapse: the neurobiology of drug- and stressinduced relapse to drug-taking. J Psychiatry Neurosci 25:125-136.

Taylor JR, Horger BA (1999) Enhanced responding for conditioned reward produced by intra-accumbens amphetamine is potentiated after cocaine sensitization. Psychopharmacology 142:31-40.

Thoenen H (1995) Neurotrophins and neuronal plasticity. Science 270:593-598.

Thomas MJ, Beurrier C, Bonci A, Malenka RC (2001) Long-term depression in the nucleus accumbens: a neural correlate of behavioral sensitization to cocaine. Nat Neurosci 4:1217-1223.

Ungless MA, Whistler JL, Malenka RC, Bonci A (2001) Single cocaine exposure in vivo induces long-term potentiation in dopamine neurons. Nature 411:583-587.

Wang Y, Chiang YH, Su TP, Hayashi T, Morales M, Hoffer BJ, Lin SZ (2000) Vitamin $\mathrm{D}(3)$ attenuates cortical infarction induced by middle cerebral arterial ligation in rats. Neuropharmacology 39:873-880.

White FJ, Kalivas PW (1998) Neuroadaptations involved in amphetamine and cocaine addiction. Drug Alcohol Depend 51:141-153.

Yamada K, Mizuno M, Nabeshima T (2002) Role for brain-derived neurotrophic factor in learning and memory. Life Sci 70:735-744. 